\title{
Case Report: Mediastinal Ganglioneuroma Presented as Chronic Diarrhea in a Young Saudi Girl
}

\author{
Khaled I. Alqoaer ${ }^{*}$, Muflih Albalawi', Mohammed S. Alnoaiji ${ }^{2}$, Amjad Khan ${ }^{3}$ \\ ${ }^{1}$ Pediatric Department, Prince Salman North West Armed Forces Hospital Tabuk, Tabuk, Saudi Arabia \\ ${ }^{2}$ Department of Surgery, Prince Salman North West Armed Forces Hospital Tabuk, Tabuk, Saudi Arabia \\ ${ }^{3}$ Laboratory and Pathology Department, Prince Salman North West Armed Forces Hospital Tabuk, Tabuk, Saudi \\ Arabia \\ Email: dralquaer@hotmail.com, dr.muflih@gmail.com, msnoaiji@windowslive.com, \\ amjadalikhan52@hotmail.com
}

Received 13 January 2014; revised 12 February 2014; accepted 9 March 2014

Copyright (C) 2014 by authors and Scientific Research Publishing Inc.

This work is licensed under the Creative Commons Attribution International License (CC BY).

http://creativecommons.org/licenses/by/4.0/

\section{(c) (i) Open Access}

\section{Abstract}

Ganglioneuromas (GN) are rare, benign neurogenic tumors that arise from sympathetic ganglia. They are often asymptomatic. However, in rare cases, they may secrete catecholamines, vasoactive intestinal polypeptides (VIP), or androgenic hormones and manifest with flushing, symptoms of catecholamine excess or chronic diarrhea. We report a young Saudi girl with chronic secretory diarrhea, severe hypokalemia and abdominal distension. After an extensive work up, a well-defined hypodense heterogeneous mediastinal mass was noted in radio imaging. A complete recovery was seen after surgical removal of that mediastinal mass which turned to be a ganglioneuroma.

\section{Keywords}

\section{Ganglioneuroma, Mediastinum, Chronic Diarrhea, Secretory Diarrhea}

\section{Introduction}

Chronic diarrhea in childhood can be due to wide range of gastrointestinal disorders. Secretory diarrhea with active intestinal fluid secretion can be seen in a small proportion of cases. In developing world the most common cause is gastrointestinal infections. However, once this has been ruled out an occult tumor that secretes vasoactive intestinal polypeptide is an important differential diagnosis [1].

Ganglioneuromas are rare, benign neurogenic tumors that arise from sympathetic ganglia. The tumors are "Corresponding author. 
composed of mature Schwann cells, ganglion cells, and nerve fibers. Ganglioneuromas may arise anywhere along the paravertebral sympathetic plexus and occasionally from the adrenal medulla. They are often asymptomatic even if they are large. An asymptomatic mass is commonly discovered on a routine radiographic study, such as a chest radiograph. Sometimes GN cause local mass effect and patients present with cough, abdominal pain, or dyspnea. In rare cases, GN secrete sufficient quantities of catecholamines, vasoactive intestinal polypeptides (VIP), or androgenic hormones explains such symptoms as hypertension, diarrhea, and virilization [2].

We report a young Saudi girl with chronic secretory diarrhea, severe hypokalemia and abdominal distension. A complete recovery was seen after surgical removal of a mediastinal mass that turned to be a ganglioneuroma.

\section{The Case}

The patient was a 17-month-old Saudi female infant. She is the first baby for young cousin parents and was the product of a term uncomplicated pregnancy and delivered without complications. She had been growing well and thriving. She presented initially with diarrhea for five days duration. Her stools were consistently loose, watery and frequent (four to six/day) associated with non bilious/none bloody vomiting and decreased activity. Examination revealed an ill looking, moderately dehydrated girl with acceptable vital signs (temperature $36^{\circ} \mathrm{C}$, respiratory rate 40 breath/minute, blood pressure 95/48, pulse rate 120 beats/minute). There was slight gaseous abdominal distention. Height and weight were both on the 10th centile. Laboratory evaluation revealed severe hypokalemia and mild acidosis (serum potassium $2 \mathrm{mmol} / \mathrm{L}$, bicarbonate $16 \mathrm{mmol} / \mathrm{L}$ and chloride $92 \mathrm{mmol} / \mathrm{L}$ ). Other electrolytes, urea and creatinine, complete blood counts and liver function tests were all normal. Stool analysis for ova and parasite, stool cultures in addition to blood and urine cultures were all negative. The patient was admitted for rehydration and further evaluation. Soon after admission she developed persistent vomiting with increasing abdominal distension and diminished bowel sounds. Abdominal radiography confirmed the diagnosis of paralytic ilieus. She was treated conservatively with intravenous fluid and electrolyte correction, nasogastric drainage and bowel rest. Her stools continue to be frequent and loose during fasting. Abdominal ultrasound was done and it was unremarkable. The patient responded partially to the management and could be discharge home on day 18 of admission.

Three weeks later the patient was admitted again because of increasing diarrhea and progressive abdominal distension. There was no history of vomiting this time. Laboratory evaluation showed again severe hypokalemia (potassium $1.5 \mathrm{mmol} / \mathrm{L}$ ). Abdominal radiography showed multiple air fluids level and ultrasound revealed intestinal dilatation but no ascitis. Fluid and electrolytes imbalance were corrected and the patient was started on amino acid based formula feeding. Repeated stool microbiology, celiac screening with anti tissue transglutaminase IgA and serum immunoglobulins were all unremarkable. Stool for fecal elastase was done and it was normal. Urine chemistry revealed sodium of $6 \mathrm{mmol} / \mathrm{L}$, chloride $117 \mathrm{mmol} / \mathrm{L}$ and potassium $7 \mathrm{mmol} / \mathrm{L}$ while stool chemistry showed potassium $67 \mathrm{mmol} / \mathrm{L}$, sodium $53 \mathrm{mmol} / \mathrm{L}$ and chloride $95 \mathrm{mmol} / \mathrm{L}$.

CT neck, chest and abdomen was done (Figure 1) and it showed a well defined hypo dense heterogeneous mass with extensive mottled calcifications was noted in the left Para spinal of lower dorsal/upper abdominal region about $7 \times 5 \times 5 \mathrm{~cm}$ just above the compressed left hemi-diaphragm and above the left adrenal gland with mild atelectasis of the posterior left lower lung. No intra-spinal extension. There was no bony destruction. Small left retro-crural lymph nodes about $7 \mathrm{~mm}$ in diameter were seen. No hilar or mediastinal lymph nodes enlargement and no pulmonary nodules. No para-aortic lymph nodes enlargement. These findings were suggestive of left Para-spinal ganglioneuroma, however the possibility of Neuroblastoma could not be ruled out. CT guided biopsy of the mass was performed and it showed loose clusters of mature ganglion cells in abundant fibrillary background (Schwannian stroma $>50 \%$ ). There were foci of calcification, very mild lymphocytic infiltration and occasional mitoses (1/100 cells). There were no necrosis or neublastic foci. The histopathology was in favor of mature ganglioneuroma. Bone scan study showed tracer uptake in the known left paraspinal mass but the rest of the scan was unremarkable.

The patient underwent surgical excision of the mass. A $9.5 \times 3 \times 5 \mathrm{~cm}$ mediastinal mass in the weighing 102 gram was found and resected (Figure 2(a) and Figure 2(b)). Microccopic examination of that mass showed spindle shaped cellular proliferates with pale eosinophilic cytoplasm, focal calcification, few immature and many mature ganglionic cells (Figure 3). Immunohistological analysis was positive for S-100 in the ganglion cell rich area but no enhanced proliferative activity (Ki67). This picture was compatible with the diagnosis of mature ganglioneuroma. The diarrhea subsided soon after surgery. Further follow up for more than one year 


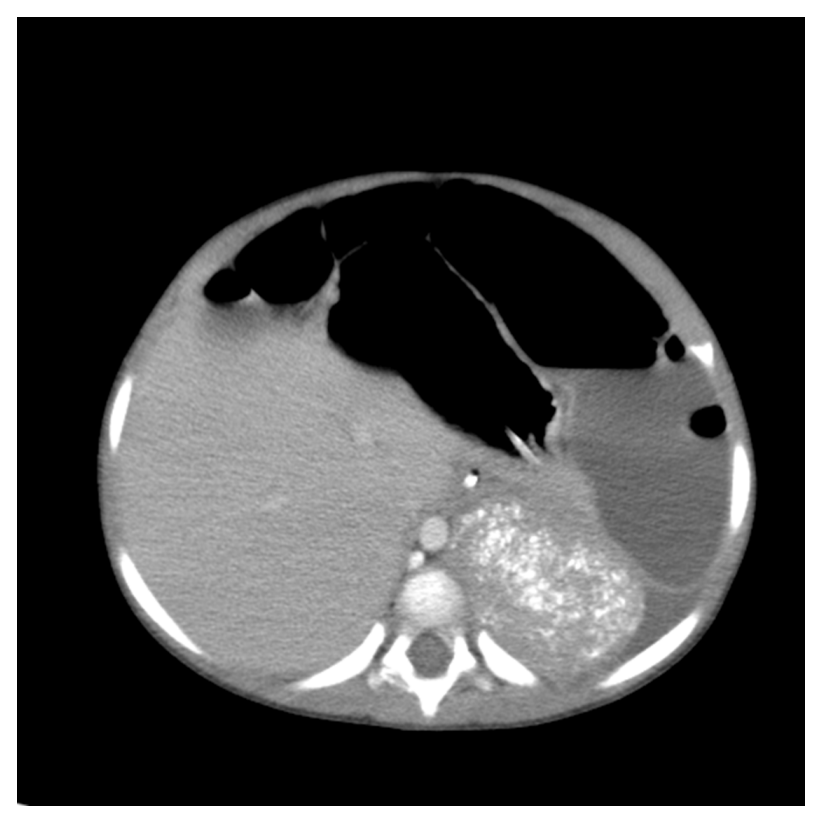

Figure 1. CT chest and abdomen showed a well defined hypo dense heterogeneous mass with extensive mottled calcifications in the left Para spinal region.

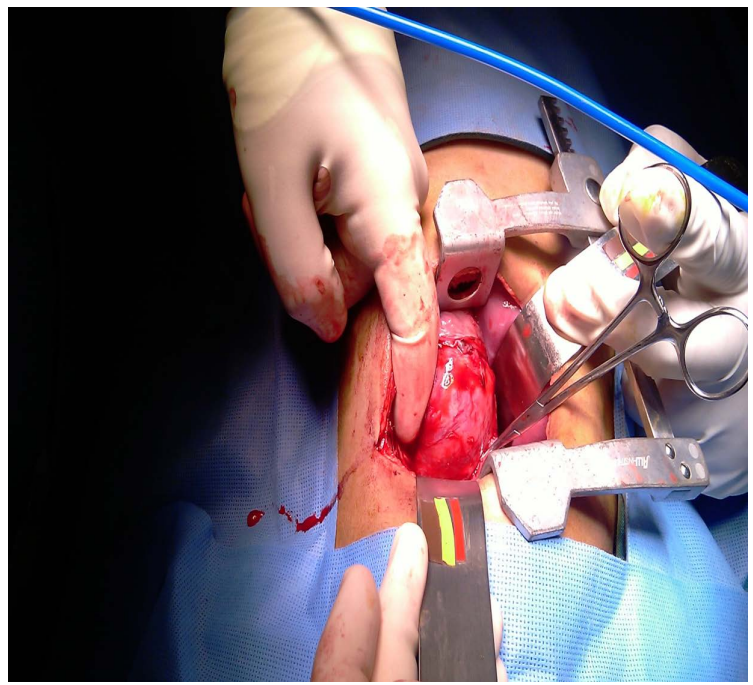

(a)

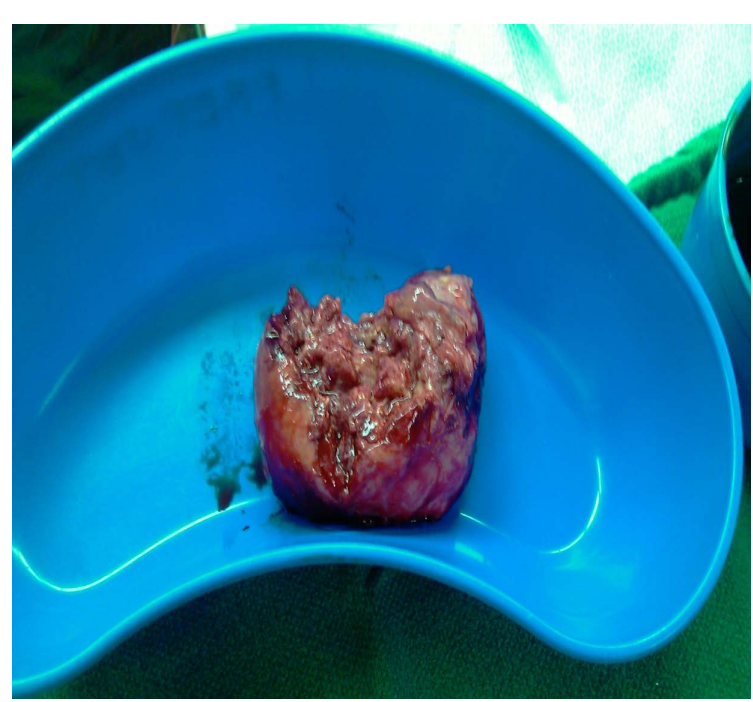

(b)

Figure 2. (a) and (b) The mediastinal mass before and after resection.

after surgery did not show any complications or recurrence of symptoms.

\section{Discussion}

Ganglioneuromas GN are rare, benign neurogenic tumors that arise from sympathetic ganglia or from anywhere along the paravertebral sympathetic plexus and occasionally from the adrenal medulla. The tumors are composed of mature Schwann cells, ganglion cells, and nerve fibers. The retroperitoneum and posterior mediastinum are the two most common locations for a ganglioneuroma, followed by the cervical region. Children and young adults are predominantly affected. The prognosis is excellent, and recurrence is rare after surgical resection [2].

GN most often manifests as an asymptomatic mass discovered on a routine radiographic study, such as a chest radiograph. Sometimes GN causes local mass effect and patients present with cough, abdominal pain, or dyspnea 


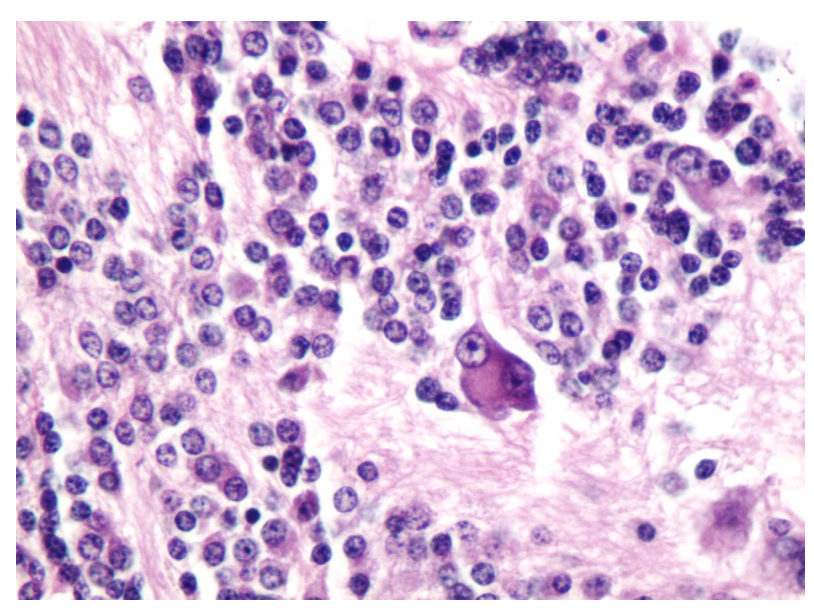

Figure 3. Microscopic examination showed spindle shaped cellular proliferates with pale eosinophilic cytoplasm, focal calcification, few immature and many mature ganglionic cells.

in rare cases, GN secretes sufficient quantities of Vanillyl mandelic acid VMA or Homovanillic acid HVA to manifest with flushing and other symptoms of catecholamine excess [3]. In the largest series of GNs to date (49 cases), 37\% of the patients had elevated VMA or HVA levels [4].

The association between a functioning ganglioneuroma and persistent watery diarrhea was reported in 1952 by Hawfield and Daisley [5]. In 1958 Verner and Morrison' described two cases of severe watery diarrhea associated with non-insulin secreting islet cell adenomas of the pancreas. This association has variously become known as the Verner-Morrison syndrome, the WDHA syndrome (watery diarrhea, hypokalemia, and achlorhydria), or pancreatic cholera [6]. In 1970 a vasoactive intestinal peptide (VIP) was first isolated from hog small intestine by Said and Mutt, and it is now known to provoke increased fluid secretion into the bowel and diarrhea [7]. In 1973 raised plasma and tumor concentrations of VIP were found in patients with a ganglioneuroblastoma and secretory diarrhea [8]. Other neural crest tumors, including neuroblastomas, have since been described in patients with severe diarrhea [9]-[11] [12].

VIP is a biologically-active polypeptide of 28 amino-acid residues. It can cause watery diarrhoea syndrome by the following mechanisms: 1) stimulation of adenylate cyclase activity and secretion of intestinal mucosa; 2) both splanchnic and systemic vasodilatation; and 3) inhibition of both pentagastrin- and histamine-stimulated gastric acid secretion. These effects would explain the clinical symptoms of this syndrome-such as severe refractory watery diarrhoea, hypokalaemia, flushing attacks, and achlorhydria [13].

A syndrome of watery diarrhoea, hypokalaemia and achlorhydria (WDHA) is caused by vasoactive intestinal polypeptide (VIP)-producing tumors. In 2009 Zhang et al. reviewed 63 reported cases in children with WDHA syndrome and showed that many of the cases presented with non-treatable watery diarrhea, hypokalemia [14]. Achlorhydria is not necessarily part of the WDHA syndrome. The range of ages at the time of diagnosis of these reported cases was from 2 months to 11 years. Among the 63 tumors, 35 were ganglioneuroblastoma (55.6\%), 20 were ganglioneuroma (31.7\%), five neuroblastoma (7.9\%), one was neurofibroma (1.6\%) and one was neurofibromatosis (1.6\%). Eleven of the total cases were in the thorax [14]. Harris et al. reported one more case of mediastinal GN ( $4.3 \mathrm{~cm}$ by $2.8 \mathrm{~cm}$ by $2.8 \mathrm{~cm}$ ) with WDHA syndrome and high serum level of VIP in an 18.5 months old girl [15]. To the best of our knowledge no more cases of mediastinal GN with diarrhea syndrome had been reported since then and interestingly this is the first reported case from Saudi Arabia.

VIP level was not done in our patient. However, the clinical presentation of watery diarrhea, severe hypokalemia and abdominal distension in addition to the immediate cessation of the diarrhea after resection of the tumor and after excluding other possible etiologies like infections and malabsorption disorders were all in keeping with the clinical diagnosis of VIP-producing ganglioneuroma that would explain this constellation of findings.

\section{Conclusion}

In conclusion, we do suggest that in any patient with chronic diarrhea of unknown etiology, VIP-secreting tumor should be considered. It is important to perform gastrointestinal, abdominal and chest ultrasound and/or CT scan 
to exclude this diagnosis. High index of suspicion is important in such cases in order to make early diagnosis and treatment.

\section{References}

[1] Guarino, A. and De Marco, G. (2004) Persistent Diarrhea. In: Walker, W.A., Ed., Text Book of Pediatric Gastrointestinal Disease, 4th Edition, BC Decker Inc., 180-193.

[2] Rha, S.E., Byun, J.Y., Jung, S.E., Chun, H.J., Lee, H.G. and Lee, J.M. (2003) Neurogenic Tumors in the Abdomen: Tumor Types and Imaging Characteristics. Radio Graphics, 23, 29-43. http://dx.doi.org/10.1148/rg.231025050

[3] Lonergan, G.J., Schwab, C.M., Suarez, E.S. and Carlson, C.L. (2002) From the Archives of the AFIP Neuroblastoma, Ganglioneuroblastoma, and Ganglioneuroma: Radiologic-Pathologic Correlation. Radio Graphics, 22, 911-934. http://dx.doi.org/10.1148/radiographics.22.4.g02jl15911

[4] Geoerger, B., Hero, B., Harms, D., Grebe, J., Scheidhauer, K. and Berthold, F. (2001) Metabolic Activity and Clinical Features of Primary Ganglioneuromas. Cancer, 91, 1905-1913. http://dx.doi.org/10.1002/1097-0142(20010515)91:10<1905::AID-CNCR1213>3.0.CO;2-4

[5] Hawfield, H.H. and Daisley Jr., G.W. (1952) A Report of a Case of a Functional Adrenal Ganglioneuroma. Clinical Proceedings Children's Hospital of the District of Columbia, 8, 98-105.

[6] Verner, J.V. and Morrison, A.B. (1958) Islet Cell Tumor and a Syndrome of Refractory Watery Diarrhea and Hypokalemia. American Journal of Medicine, 25, 374-380. http://dx.doi.org/10.1016/0002-9343(58)90075-5

[7] Said, S.I. and Mutt, V. (1970) Potent Peripheral and Splanchnic Vasodilator Peptide from Normal Gut. Nature, 225, 863-864. http://dx.doi.org/10.1038/225863a0

[8] Bloom, S.R., Polak, J.M. and Pearse, A.G. (1973) Vasoactive Intestinal Peptide and Watery-Diarrhoea Syndrome. Lancet, 2, 14-16. http://dx.doi.org/10.1016/S0140-6736(73)91947-8

[9] Swift, P.G., Bloom, S.R. and Harris, F. (1975) Watery Diarrhoea and Ganglioneuroma with Secretion of Vasoactive Intestinal Peptide. Archives of Disease in Childhood, 50, 896-899. http://dx.doi.org/10.1136/adc.50.11.896

[10] Iida, Y., Nose, O., Kai, H., Okada, A., Mori, T., Lee, P.K., Kakudo, K. and Yanaihara, N. (1980) Watery Diarrhoea with a Vasoactive Intestinal Peptide-Producing Ganglioneuroblastoma. Archives of Disease in Childhood, 55, 929-936. http://dx.doi.org/10.1136/adc.55.12.929

[11] Long, R.G., Bryant, M.G., Mitchell, S.J., Adrian, T.E., Polak, J.M. and Bloom, S.R. (1981) Clinicopathological Study of Pancreatic and Ganglioneuroblastoma Tumours Secreting Vasoactive Intestinal Polypeptide (Vipomas). British Medical Journal (Clinical Research Ed.), 282, 1767-1771. http://dx.doi.org/10.1136/bmj.282.6278.1767

[12] Socha, J., Dobrzańska, A., Rowecka, K., Cichy, W., Bierła, J., Stodulski, J., et al. (1984) Chronic Diarrhea Due to VIPoma in Two Children. Journal of Pediatric Gastroenterology and Nutrition, 3, 143-148. http://dx.doi.org/10.1097/00005176-198401000-00027

[13] Murphy, M.S., Sibal, A. and Mann, J.R. (2000) Persistent Diarrhoea and Occult Vipomas in Children. BMJ, 320, 15241526. http://dx.doi.org/10.1136/bmj.320.7248.1524

[14] Zhang, W.Q., Liu, J.F., Zhao, J., Zhao, S.Y. and Xue, Y. (2009) Tumor with Watery Diarrhoea, Hypokalaemia in a 3-Year-Old Girl. European Journal of Pediatrics, 168, 859-862. http://dx.doi.org/10.1007/s00431-008-0898-4

[15] Leleiko, N.S., Gee, M.S. and Sadow, P.M. (2010) An 18.5-Month-Old Girl with Watery Diarrhea and Poor Weight Gain. New England Journal of Medicine, 362, 1619-1626. http://dx.doi.org/10.1056/NEJMcpc0910932 